\title{
Motivação para aprender em adolescentes do Ensino Médio de uma escola pública militar
}

\author{
Ana Carla Marostica de Souza ${ }^{1}{ }^{1}$ \\ Aline Cardoso Siqueira $\left(^{2}\right.$ \\ Israel Kujawa (i) ${ }^{1}$ \\ Naiana Dapieve Patias (10 1 \\ ${ }^{I}$ IMED, RS, Brasil. \\ ${ }^{2}$ Universidade Federal de Santa Maria, RS, Brasil.
}

\begin{abstract}
Resumo
A motivação para aprender é objeto de estudo de inúmeras disciplinas do conhecimento, pois está relacionada com a aprendizagem escolar. Este estudo objetiva investigar a motivação intrínseca (MI) e extrínseca (ME) em adolescentes do Ensino Médio de uma escola militar, verificando quais as diferenças nos tipos de motivação por sexo e faixa etária. Participaram 236 adolescentes de 14 a 18 anos $(M=15,5 ; D P=0,84)$ de ambos os sexos, sendo $138(59 \%)$ meninas. Foram utilizados como instrumentos para coleta de dados a Escala de Avaliação da Motivação para Aprender de Alunos do Ensino Médio (EMA-EM) e uma ficha de dados sociodemográficos. Foram realizadas análises estatísticas descritivas e teste t de Student. Os resultados evidenciaram que a MI é maior do que a ME. Quanto à faixa etária, houve diferença significativa apenas quanto à motivação total, tendo os adolescentes mais novos mais motivação do que os mais velhos. Os resultados são discutidos com base na teoria motivacional intrínseca e extrínseca e demonstram que, no geral, os adolescentes estão motivados para a aprendizagem.
\end{abstract}

Palavras chave: adolescência, Ensino Médio, motivação intrínseca, motivação extrínseca.

\section{Motivation to learn in High School students of a public military school}

\begin{abstract}
Motivation to learn is the object of study of many subject areas of knowledge as it relates to school learning. This study aims to investigate the motivation to learn and its components intrinsic motivation/IM and extrinsic motivation/EM in high school adolescents of a military school, checking differences in the types of motivation by gender and age. Participants were 236 adolescents aged 14 to 18 years old $(M=15.5, \mathrm{SD}=0.84)$ of both genders, being $138(59 \%)$ girls. They were used as instruments for data collection The Learning Motivation Assessment Scale for High School Students (EMA-EM) and a form of socio-demographic data. Data analyzes were performed using descriptive statistical analysis and Student's test. The results showed that the IM is greater than the EM. In relation to age, there was only a significant difference for total motivation, with younger teens being more motivated than the elders. The results are discussed based on the intrinsic and extrinsic motivational theory and demonstrate that, in general, adolescents are motivated to learn.
\end{abstract}

Keywords: adolescence, High School, intrinsic motivation, extrinsic motivation.

\section{Motivación para aprender en los estudiantes de la secundaria de una escuela pública militar}

Resumen

La motivación para aprender es objeto de estudio en numerosas disciplinas del conocimiento, ya que se relaciona con el aprendizaje escolar. Este estudio tiene como objetivo investigar la motivación para aprender y sus componentes (motivación intrínseca/MI y extrínseca/ME) en adolescentes de la escuela secundaria, comprobando las diferencias en los tipos de motivación por sexo y por edad. Participaron 236 adolescentes de 14 a 18 años $(M=15,5 ; D E=0,84)$ de ambos sexos, y $138(59 \%)$ niñas. Fueron utilizados como instrumentos para la recolección de datos la Motivación para Aprender de Alumnos de la Escuela Secundária (EMA-ES) y una forma de datos sociodemográficos. Los datos fueron analizados utilizando el análisis estadístico descriptivo y prueba $t$ de Student. Los resultados mostraron que la MI es mayor que la ME. Cuanto a la edad, no hubo una diferencia significativa, sólo para la motivación total, con los adolescentes más jóvenes siendo más motivados que sus mayores. Los resultados se discuten en base a la teoría de la motivación intrínseca y extrínseca y demuestran que, en general, los adolescentes están motivados para el aprendizaje.

Palabras clave: adolescencia, Escuela Secundaria, motivación intrínseca, motivación extrínseca. 


\section{Introdução}

A educação das crianças e dos adolescentes é foco de interesse tanto da comunidade científica quanto dos gestores de uma nação. $\mathrm{O}$ direito à educação está entre os fundamentais para toda a criança e adolescente de até 18 anos incompletos no Brasil. Dados do Censo Escolar do Ministério da Educação e do Instituto Nacional de Estudos e Pesquisas Educacionais Anísio Teixeira (INEP, 2018) evidenciaram que, no Brasil, em 2018, haviam 7.930.384 alunos matriculados no Ensino Médio. A maior parte das matrículas (6.407.190) na rede estadual de ensino, sendo $7,9 \%$ matriculados em escolas de turno integral. Do total de alunos matriculados, os dados indicaram uma taxa de $28,2 \%$ de distorção entre idade-série e $58,5 \%$ de insucesso escolar considerada a soma do abandono e reprovações nos três anos do Ensino Médio. No geral, os dados indicam a necessidade de estudos que evidenciem os aspectos relacionados ao insucesso escolar de alunos do Ensino Médio, já que há um expressivo percentual de reprovação e abandono.

Historicamente, a escola pública brasileira tem demonstrado casos de fracasso escolar, os quais podem ser compreendidos por meio de reprovações e, consequentemente, distorção entre idade e série (Pezzi, Donelli, \& Marin, 2016). Esse fracasso, por vezes, pode se constituir como fator de risco para o abandono escolar (Damiani, 2006; Miguel, Rijo, \& Lima, 2014). Autores afirmam que há uma complexidade de elementos que influenciam para o melhor ou pior rendimento dos alunos (Angelucci, Kalmus, Paparelli, \& Patto, 2004; Eccheli, 2008; Miguel et al., 2014; Moreira \& Kramer, 2007; Prata, BarbosaDucharne, Gonçalves, \& Cruz, 2013; Schulze \& Van Heerden, 2015; Zardeckaite-Matulaitiene \& Paluckaite, 2013).

A partir de uma revisão de dissertações e teses sobre a história do fracasso escolar em escolas públicas, Angelucci et al. (2004) mencionam que o fracasso pode ser explicado por três principais aspectos: a) individuais do aluno - fracasso como déficit intelectual, como problema psíquico ou como inibição intelectual adquirida de relações familiares disfuncionais; b) como um problema técnico - a causa do fracasso encontrase no método de ensino do professor, ou c) como uma questão institucional - a escola reproduz as relações sociais desiguais e produz o fracasso. Além disso, o fracasso escolar tem sido considerado consequência de um conjunto de fatores individuais (do próprio aluno), familiares e ambientais (escolares) (Miguel et al., 2014). Dentre os aspectos individuais do próprio aluno, pode estar presente a desmotivação. De fato, muitas vezes, o fracasso e o abandono têm sido relacionados pelos educadores com a falta de motivação dos alunos para aprender (Bzuneck, 2009).

Dentre as principais teorias sobre a motivação, estão aquelas relacionadas à motivação intrínseca e à motivação extrínseca. A primeira diz respeito à concretização da tarefa pelo fim em si mesma, ou seja, pelo prazer em realizá-la. Nessa motivação, há papel ativo do sujeito já que o mesmo é levado a agir por intencionalidade própria. Isto é, a motivação está na própria atividade de aprender, na busca de sentido e significado (Lourenço \& De Paiva, 2010; Schwartz, 2014). Esse tipo de motivação está relacionado ao maior desempenho escolar (Lin, McKeachie, \& Kim, 2003). Por outro lado, a motivação extrínseca refere-se ao papel dos reforços e castigos, muitas vezes utilizados pela escola em forma de conceitos e notas, enfatizando as consequências do comportamento (Lourenço \& De Paiva, 2010). Assim, na motivação extrínseca, o motivo para aprender não está dentro do sujeito, mas no ambiente, na possibilidade de recompensas ou sanções (Schwartz, 2014).

Um estudo apresentado por Locatelli, Bzuneck e Guimarães (2007), desenvolvido com 206 alunos da 3 $3^{\text {a }}$ série do Ensino Médio de escolas públicas estaduais e privadas de uma localidade da região norte do Paraná, com idades entre 15 e 19 anos, afirma que estudantes que estão motivados com o tempo futuro e que traçam metas apresentam melhor desempenho escolar. São estudantes que focam seu intelecto nos estudos, fazendo uso de estratégias de ensino, motivandose positivamente quando interpretam a tarefa como significativamente relevante e interessante, estudam com maior eficiência, produzem mais conhecimento e tiram boas notas.

Um estudo realizado com 1376 alunos de $4^{a}$ a $8^{\text {a }}$ série do Ensino Fundamental de escolas públicas e privadas, demonstrou um declínio significativo da motivação intrínseca dos estudantes e um leve aumento da motivação extrínseca com a evolução das séries. Em relação ao sexo, os autores verificaram médias mais altas na desmotivação em meninos do que nas meninas. Já na motivação intrínseca, as meninas obtiveram médias mais altas quando comparadas com os meninos (Rufini, Bzuneck, \& Oliveira, 2012).

As diferenças na motivação para aprender de acordo com a idade são descritas por Bzuneck (2009). $\mathrm{O}$ autor afirma que, à medida que os alunos avançam no nível de ensino, o interesse tende a decair e as dúvidas quanto à própria capacidade de aprender tendem a aumentar. Desta forma, para o autor, são praticamente inexistentes os problemas de motivação nos primeiros anos do ensino básico. 
No entanto, nem todos os estudos encontraram uma diminuição na motivação para aprender com o aumento da idade. Estudos de Boruchovitch (2008) e Guimarães, Bzuneck e Sanches (2002) indicam haver um aumento na motivação com o passar dos anos demonstrando que não há consenso na literatura sobre a variável idade ou faixa etária nas mudanças relacionadas à motivação para aprender. Também não há consenso sobre o sexo nas variações da motivação para aprender, sendo que alguns autores encontraram mais motivação em meninos (Marchiore \& Alencar, 2009) e outros, mais motivação para aprender em meninas (Boruchovitch, 2008; Guimarães et al., 2002).

Ainda que o estudo de Bzuneck (2010) tenha focalizado a infância, ele evidenciou um dado relevante para a compreensão do fenômeno sobre a percepção de confiança em si mesmo, apontando que o desempenho está mais relacionado à crença da autoeficácia do que ao nível de inteligência, tendo em vista que crianças desmotivadas, com conceitos de desvalia e crença de falta de capacidade, apresentaram menor desempenho do que crianças motivadas que apresentavam bom autoconceito. No mesmo sentido, o estudo de Kolenc (2011) encontrou associação significativa entre autoconceito e motivação para aprender entre universitários. Já um estudo realizado com estudantes do Ensino Médio na África do Sul vai de encontro aos achados de Bzuneck (2010), evidenciando que o maior peso para a motivação para aprendizagem está no ambiente, nos objetivos que a escola estabelece para a aprendizagem e no perfil dos professores.

Considerando que a idade e o sexo são fatores não consensuais na literatura e que além deles, o ambiente escolar influencia na motivação para aprender, as escolas públicas militares, por suas especificidades, necessitam de investigação. Embora os estudos sobre motivação para aprender abarquem o Ensino Fundamental, Médio e Superior, nenhum dos estudos teve como foco o público adolescente de escolas estaduais militares. Mesmo sendo públicas, estas escolas destacam-se pela sua disciplina, hierarquia e bom desempenho dos alunos. De fato, um estudo que teve o intuito de investigar os fatores que contribuem para o bom desempenho escolar dos alunos de escolas militares em provas como as do ENEM (Exame Nacional do Ensino Médio), verificou que, para ingressar na escola militar, o aluno necessita realizar uma prova de seleção, sendo esta discriminativa no sentido de que apenas os "bons estudantes" - que atingem as médias nas provas de seleção - conseguem adentrar na escola (Benevides \& Soares, 2016).

Ainda sobre o desempenho escolar de alunos do ensino médio de escolas militares, um estudo realizado em dez escolas do Ceará investigou, por meio de entrevistas com gestores, docentes, alunos e funcionários, as características das escolas que possuem bom desempenho no ENEM e as com baixo desempenho. Os resultados indicaram que, das dez escolas investigadas, duas eram militares e o sucesso escolar destas escolas advém da seleção inicial para adentrar na escola, a qual "elimina" alunos menos preparados e que possuem dificuldades escolares. Ainda, o bom desempenho é influenciado pela autoridade docente e dos pais e da capacitação e disponibilidade docente para com os alunos (Haguette, Pessoa, \& Vidal, 2016).

Considerando as estatísticas negativas sobre desempenho escolar das escolas públicas brasileiras e a escassez de trabalhos científicos sobre a motivação para aprender em adolescentes de escolas militares e suas especificidades, o presente estudo objetivou analisar a motivação para aprender em adolescentes estudantes de Ensino Médio de uma escola pública militar do interior do Rio Grande do Sul. Além disso, como objetivos específicos, verificou se haviam diferenças estatisticamente significativas na motivação total, intrínseca e extrínseca por sexo e faixa etária.

\section{Método}

\section{Delineamento e participantes}

Trata-se de uma pesquisa quantitativa, descritiva e transversal, na qual participaram 236 estudantes com idade média de 15,5 anos $(\mathrm{DP}=0,84)$ de ambos os sexos, sendo 138 (59\%) meninas. Os critérios de inclusão foram: ter entre 14 e 18 anos incompletos, estarem matriculados no Ensino Médio de uma escola pública estadual de uma cidade do interior do Rio Grande do Sul. A escola participante atende apenas o público adolescente por meio do Ensino Médio e possui características específicas, como o foco na disciplina dos alunos, pois trata-se de uma escola militar.

\section{Instrumentos}

Os adolescentes responderam à Escala de Avaliação da Motivação para Aprender de Alunos do Ensino Médio (EMA-EM) (Neves \& Boruchovitch, 2007) a qual inclui afirmativas sobre a motivação, além de um questionário sobre dados sociodemográficos como idade, sexo e ano escolar. A escala EMA-EM é uma versão reformulada da Escala de Avaliação da Motivação para Aprender para Alunos do Ensino Fundamental (Neves \& Boruchovitch, 2007). A versão para o Ensino Médio compõe-se de 34 afirmativas a serem respondidas em uma escala likert de três pontos (nunca, às vezes e sempre) e tem como objetivo avaliar 
a motivação da aprendizagem em alunos de Ensino Médio. No estudo das autoras da escala, análises de consistência interna revelaram coeficiente de Cronbach igual a 0,80 . A mesma é composta por dois fatores, cada um com 17 afirmativas: o primeiro chamado de Motivação Intrínseca $(a=0,86)$ e o segundo de Motivação Extrínseca $(a=0,80)$.

\section{Procedimentos e considerações éticas}

A escola pública militar da cidade foi contatada para a apresentação do projeto, tendo sido feito o convite para integrar a pesquisa. $\mathrm{O}$ novo contato com a escola participante se deu após a aprovação do projeto pelo Comitê de Ética em Pesquisa da IMED. Assim, foram realizadas visitas à escola participante, nas quais alunos de primeiro, segundo e terceiro ano do Ensino Médio foram convidados a participar. As pesquisadoras apresentaram o projeto aos alunos em reuniões com pequenos grupos (turmas), durante as quais foram explicados os objetivos do projeto e a voluntariedade na participação. Aos alunos que desejaram participar, entregou-se uma via do Termo de Consentimento Livre e Esclarecido (TCLE) para assinatura do responsável, consentindo sua participação. Além disso, os alunos assinaram um Termo de Assentimento (TA), assentindo sua participação. A coleta de dados ocorreu em dia e espaço previamente combinados com a escola e com os alunos e foi de forma coletiva, realizada por alunos de um curso de graduação em Psicologia previamente treinados pela coordenadora do projeto. A aplicação teve duração média de 20 minutos.

O projeto maior do qual este estudo faz parte intitula-se $O$ que motiva adolescente a aprender $e$ permanecer na escola e teve como objetivo maior investigar a motivação para aprender e variáveis associadas por meio de uma pesquisa mista (quanti e qualitativa). O projeto foi aprovado pelo Comitê de Ética em Pesquisa de uma instituição de ensino superior, cujo protocolo correspondente é CAAE 56453116.4.0000.5319. A pesquisadora forneceu todas as informações pertinentes aos estudantes, esclarecendo sobre o objetivo do estudo, o caráter confidencial, sigiloso e voluntário. Esses direitos foram assegurados através do TCLE, regido de acordo com a Resolução no 510/2016 do Conselho Nacional de Saúde. O estudo pode ser considerado de risco mínimo por tratar-se de um tema neutro que não possui evidente impacto na vida dos participantes. Contudo, foi oferecida a oportunidade de conversar com as pesquisadoras em caso de desconforto, como também, possível amparo psicológico. Não foi identificada nenhuma situação de desconforto psicológico.

\section{Análise dos dados}

Após a aplicação do instrumento, os dados foram digitalizados no programa estatístico Statistical Package for the Social Sciences (SPSS) versão 22.0. A análise dos dados do instrumento se deu por meio de tratamento estatístico dos dados, sendo utilizadas análises descritivas (médias, desvios padrão) da idade, do sexo e da motivação total, intrínseca e extrínseca. A fim de verificar a diferença na motivação total, intrínseca e extrínseca em relação ao sexo e faixa etária dos participantes, testes $t$ de student foram realizados após testada a normalidade na distribuição amostral. Além disso, teste $t$ de student foi realizado para comparar diferenças entre os sexos por afirmativa.

\section{Resultados}

A maioria dos participantes cursava o $1^{\mathrm{O}}$ ano (100 adolescentes $-42 \%$ ), seguido de participantes matriculados no 3 o ano (74 adolescentes $-31 \%$ ) e no $2^{\mathrm{O}}$ ano (61 estudantes - 26\%), sendo esse número igual ao número de matriculados no Ensino Médio na escola na data da aplicação dos instrumentos. A Tabela 1 possui a descrição dos escores mínimo e máximo, média e dp da MT, ME e MI.

TABELA 1

Escores máximos, mínimos, médias e desvio padrão na motivação total, intrínseca e extrínseca

\begin{tabular}{lcccc}
\hline & Mínimo & Máximo & $M$ & $D P$ \\
Motivação Total & 53 & 88 & 68,31 & 5,17 \\
Motivação intrínseca & 23 & 51 & 41,00 & 5,49 \\
Motivação extrínseca & 17 & 47 & 27,31 & 5,19 \\
\hline
\end{tabular}

Na Tabela 2, são apresentadas as médias, os desvios-padrão e os resultados de comparação de médias na motivação total, intrínseca e extrínseca por sexo. $\mathrm{O}$ resultado do teste $t$ indicou não haver diferenças estatisticamente significativas em nenhum tipo de motivação por sexo.

TABELA 2

Médias e desvio padrão na motivação total, intrínseca e extrínseca por sexo

\begin{tabular}{|l|l|c|c|c|c|}
\hline & & $M$ & $D P$ & $T$ & $p$ \\
\hline Motivação Total & Meninos & 67,58 & 5,46 & $-1,80$ & 0,07 \\
& Meninas & 68,83 & 4,91 & & \\
\hline \multirow{2}{*}{ Motivação intrínseca } & Meninos & 40,21 & 5,47 & $-1,85$ & 0,06 \\
& Meninas & 41,55 & 5,45 & & \\
\hline \multirow{2}{*}{ Motivação extrínseca } & Meninos & 27,37 & 5,05 & \multirow{2}{*}{0,13} & 0,89 \\
& Meninas & 27,28 & 5,31 & & \\
\hline
\end{tabular}


Na Tabela 3, são apresentados as médias, os desvios-padrão e os resultados de comparação de médias na motivação total, intrínseca e extrínseca por faixa etária (adolescentes mais novos, 14 a 15 anos, e mais velhos, 16 a 18 anos), distribuídos em dois grupos, conforme a mediana. O resultado do teste $t$ indicou que há diferenças estatisticamente significativas apenas na motivação total, tendo os adolescentes mais novos, maior MT quando comparados aos adolescentes mais velhos.

TABELA 3

Médias e desvio padrão na motivação total, intrínseca e extrínseca por faixa etária

\begin{tabular}{llcccc}
\hline & & $M$ & $D P$ & $T$ & $p$ \\
\hline Motivação Total & Mais novos & 69,02 & 5,45 & \multirow{2}{*}{2,45} & \multirow{2}{*}{0,01} \\
& Mais velhos & 67,40 & 4,67 & & \\
Motivação intrínseca & Mais novos & 41,34 & 5,62 & \multirow{2}{*}{1,10} & 0,27 \\
& Mais velhos & 40,55 & 5,30 & & \\
Motivação extrínseca & Mais novos & 27,68 & 5,90 & \multirow{2}{*}{1,25} & 0,21 \\
& Mais velhos & 26,84 & 4,76 & & \\
\hline
\end{tabular}

Foram investigadas as médias por afirmativa dos itens da EMA-EM. As que obtiveram maiores médias foram aquelas relacionadas à motivação intrínseca. Já as menores médias foram constatadas nos itens que diziam respeito à motivação extrínseca. A fim de investigar se havia diferença por sexo, nas afirmativas, o teste $t$ de student foi realizado. Esta análise indicou diferenças estatisticamente significativas, tendo as meninas, maiores médias, quando comparadas aos meninos em algumas afirmativas relacionadas à motivação intrínseca da importância do estudo em si e não por reforços externos. Já os meninos, obtiveram maior média quando comparados às meninas em uma afirmativa relacionada à motivação extrínseca sobre a idealização de um emprego.

\section{Discussão}

Este estudo apresentou informações relevantes quanto ao entendimento da motivação para aprender entre adolescentes, especialmente quanto à mensuração da motivação intrínseca e da extrínseca. Embora a motivação intrínseca seja um aspecto importante para os adolescentes aprenderem, Boruchovich (2008) considera que não se deve excluir a motivação extrínseca, pois as duas são importantes no processo de aprendizagem dos alunos, sendo uma complementar à outra. Alunos motivados intrinsecamente tendem a ser mais ativos em sala de aula, engajam-se com maior facilidade nas atividades. Além disso, a motivação intrínseca é educacionalmente mais desejada, já que promove a autonomia dos alunos. Já a motivação extrínseca refere-se a fatores ambientais que reforçam ou não o comportamento de engajamento dos alunos às tarefas.

Para Bzuneck (2009), é errôneo dizer que o aluno é desmotivado, pois não é possível generalizar a todo universo escolar. Ou seja, o aluno pode ser desmotivado para uma disciplina, um professor ou alguns aspectos específicos de alguma matéria escolar, sendo, então, correto afirmar que a motivação ou a falta dela está circunscrita a certas condições ou fatores. De fato, as análises do presente estudo demonstraram que os adolescentes estão motivados pela aprendizagem em si, pelo gosto de aprender, uma vez que as médias na motivação intrínseca são maiores quando comparadas com a motivação extrínseca quando comparada com a motivação extrínseca. Isso quer dizer que os adolescentes participantes deste estudo estão motivados pela aprendizagem em si e não apenas para evitar a punição ou receber algum tipo de reforço. De certa forma, este resultado contraria aspectos percebidos no dia a dia da escola, na qual os professores têm ressaltado a falta de motivação para aprender dos estudantes, sem haver uma diferenciação (Bzuneck, 2009).

Cabe ressaltar que os participantes do estudo são adolescentes de uma escola pública militar que, comparada com outras escolas públicas, possui diferenciais. Por exemplo, em um estudo realizado com docentes e estudantes de uma escola militar, os resultados indicaram que, além do modelo de gestão, os alunos consideram a escola militar melhor que a de seus amigos, sendo uma opção, junto com a decisão dos pais, estudar nela. O estudo ainda indica que a disciplina, o respeito as regras, a capacitação dos professores e o interesse deles são diferenciais da escola em que estudam. Já os professores, consideram que o bom desempenho escolar é fruto de uma boa gestão, regras da escola (respeito à hierarquia e normas disciplinares estabelecidas), capacitação dos professores, salário diferenciado e bons recursos da escola (Bonfim, Damasceno, Soares, Rodrigues, \& Fernandes, 2017). Esses aspectos podem ter influenciado os resultados, principalmente, relacionados à motivação intrínseca dos alunos investigados.

De fato, no presente estudo, quando investigadas por afirmativa, as maiores médias gerais referemse à motivação intrínseca e as menores, à motivação extrínseca, podendo significar que os alunos gostam de ser desafiados ao aprenderem e possuem motivações individuais para aprender. Esse aspecto é essencial, pois demonstra que os alunos têm interesse em aprender e não o fazem apenas para obter recompensas ou evitar 
a punição. Assim, observando-se as menores médias nas afirmativas, elas revelaram que o que menos importa para esses adolescentes é o reforço externo, ou seja, a motivação extrínseca, tendo em vista as médias nos itens. Pode-se pensar que, o fato de ser uma escola militar pode ter influenciado os achados. Ainda, considerando que os participantes adolescentes e matriculados no Ensino Médio, estão vivenciando um momento crucial de organização e planejamento de vida, especialmente no que se refere à escolaridade $\mathrm{e}$ ao futuro, sendo, então, compreensível que os itens de motivação intrínseca tenham se destacado.

Os resultados do estudo atual apresentam concordâncias, mas também discordâncias, do estudo de Marchiore e Alencar (2009), realizado para avaliar a motivação de 364 adolescentes, estudantes do Ensino Médio, de escolas públicas e privadas. De forma similar ao estudo que foi apresentado neste artigo, os autores evidenciaram que a motivação intrínseca obteve maior média geral, tanto na escola pública quanto na escola privada. Porém, diferentemente do estudo atual, as afirmativas com maior pontuação diziam respeito à motivação extrínseca, indicando que apesar dos estudantes estarem motivados intrinsecamente, eles apresentam pouca motivação para estudar assuntos os quais não veem sentido em aprender ou apenas assuntos que servirão para a obtenção da nota. Esse dado evidencia a importância em dispor aos adolescentes, metodologias que os instiguem e que os desafiem, pois elas favorecerão o engajamento dos mesmos, motivando-os.

Os resultados do presente estudo evidenciam, ainda, similaridades e diferenças com a pesquisa descrita por Neves e Boruchovitch (2004), realizada com 160 estudantes de 7 e 16 anos, do Ensino Fundamental, de uma escola pública de Campinas/SP. Os resultados indicaram maior média na motivação intrínseca, confirmando achados do estudo atual. Por outro lado, na pesquisa de Neves e Boruchovitch (2004), os alunos mais velhos apresentaram maior motivação. Ainda, as autoras indicam que a maioria dos estudantes expressou motivação para estudar em função do papel da escola na promoção social, ou seja, suas atividades são realizadas levando em conta sua autonomia, por serem consideradas satisfatórias e atraentes. Outro estudo também encontrou maior média na motivação intrínseca, o qual foi realizado por Guimarães, Bzuneck e Sanches (2002), com 246 alunos do curso de licenciatura da Universidade Estadual de Londrina. Os autores ainda indicaram que as maiores médias na motivação intrínseca foram encontradas em estudantes mais velhos (31 anos ou mais) quando comparados aos mais novos (até 21 anos), diferentemente dos achados do estudo atual. Pode-se inferir que os adolescentes estudados, por estarem em uma escola militar, vivenciem um contexto de aprendizagem diferenciado e, portanto, podem apresentar diferenças quando comparados aos adolescentes de outras escolas.

Os achados do presente estudo revelam convergências e divergências principalmente em relação a outros estudos realizados, sobre as diferenças entre sexos e idades na motivação. A respeito da diferença entre os sexos, na MT, MI e ME, o presente estudo não encontrou diferenças estatisticamente significativas, embora tenha havido diferenças estatisticamente significativas em algumas afirmativas que se referem à motivação intrínseca, tendo as meninas maiores médias. Percebe-se, dessa forma, que as meninas se esforçam em busca de conhecimento, a fim de melhorar suas habilidades, mesmo sem ter nenhum ganho secundário, pois estão intrinsecamente mais motivadas, quando comparadas aos meninos. Essa diferença pode ser compreendida por uma perspectiva de gênero, que pode sugerir que as meninas precisam aplicar esforços para serem reconhecidas por suas habilidades, para conseguir uma boa posição social e serem reconhecidas no mercado de trabalho como capazes de contribuir na sociedade. Ainda que a literatura apresente estudos que demonstram diferença entre meninas e meninos quanto à motivação para aprender (DeBacker \& Nelson, 2000) e outros em que não há diferença (Pansera, Valentini, Souza, \& Berleze, 2016; Schulze \& Van Heerden, 2015), a diferença encontrada no estudo atual pode estar relacionada às questões de gênero que, muitas vezes, podem produzir o receio de fracasso e de punição por não atenderem às expectativas.

Se as meninas sofrem influências sociais e culturais, o mesmo ocorre com os meninos, que também podem estar sendo influenciados levando-se em conta o seu pensamento de aprender para ter um bom emprego no futuro. Quando comparados com as meninas, a motivação extrínseca de ter um emprego no futuro se sobrepõe no sexo masculino. Pode-se atribuir essa motivação como indicadores a um sistema patriarcal que ainda se faz presente na sociedade atual, indicando que ao homem cabe sustentar a família, sendo o principal provedor do lar (Castells, 2000; Szapiro \& Carneiro, 2002).

Ainda no que diz respeito ao sexo, uma pesquisa realizada com 364 alunos de uma escola particular e outra pública de uma cidade de Minas Gerais, investigou a percepção de estudantes do ensino médio sobre a motivação intrínseca e extrínseca para aprender e as diferenças relacionadas ao sexo e também acerca do tipo de escola (pública e privada). A motivação esteve associada com o sexo e tipo de escola, tendo os 
adolescentes do sexo masculino e de escola particular médias superiores na motivação intrínseca e extrínseca quando comparados com os adolescentes do sexo feminino e de escolas públicas (Marchiore \& Alencar, 2009).

Sobre a idade, o presente estudo indicou haver diferenças estatisticamente significativas na motivação total em adolescentes mais novos e mais velhos, sendo os primeiros, mais motivados. De acordo com Bzuneck (2009), nos primeiros anos do Ensino Básico, como na pré-escola, são praticamente inexistentes os problemas de motivação. O mesmo ocorre nos anos iniciais do Ensino Fundamental. No entanto, à medida que os alunos avançam no nível de ensino, o interesse tende a decair e as dúvidas quanto a própria capacidade de aprender tende a aumentar, já que os problemas se tornam mais complexos e profundos e há um aumento do nível de exigência de diferentes tipos de disciplinas.

Por outro lado, diferentes estudos (Boruchovitch, 2008; Guimarães et al., 2002; Neves \& Boruchovitch, 2004) sugerem o oposto. Ou seja, conforme os anos passam, a motivação tanto intrínseca como extrínseca tende a aumentar. Guimarães et al. (2002), em um estudo realizado com 246 estudantes de cursos de licenciatura de Londrina, verificaram que a idade é um fator importante, pois muitos alunos estão mais maduros em relação à escolha profissional, além de já terem tentando outras possibilidades, o que pode contribuir para a maior motivação. No estudo de Boruchovitch (2008), o aumento da idade está associado ao aumento da motivação tanto da intrínseca como da extrínseca. Ainda sobre a diferença, por faixa etária, na motivação, estudo realizado por Pansera et al. (2016) não encontrou diferenças na motivação entre crianças de 9 a 10 anos.

\section{Considerações finais}

No geral, percebe-se que os adolescentes do estudo estão mais motivados intrinsecamente do que extrinsecamente, embora exista diferença entre as idades na motivação total e por sexo, sendo os adolescentes mais novos os mais motivados e as meninas mais motivadas intrinsecamente do que os meninos na análise por afirmativa. No entanto, não houve diferença estatisticamente significativa entre os sexos na motivação intrínseca e extrínseca, contrariando estudos anteriores.

$\mathrm{O}$ estudo vai de encontro às reclamações gerais de que os adolescentes não estão motivados para nada. Eles estão, mas talvez sua motivação não seja a esperada por pais e professores. De fato, para Bzuneck (2009), em termos qualitativos, algumas motivações são adaptativas e outras não. A motivação pode ocorrer de forma errônea quando, por exemplo, os alunos terminam rápido as tarefas para entregar logo ou para se destacar em relação aos outros alunos da classe. Outros aspectos importantes referem-se à motivação devido à preocupação com notas, diplomas ou ameaça de reprovação com o intuito de não parecerem incompetentes. Cabe ressaltar que embora desadaptativas, os alunos estão motivados, sendo comum este tipo de situação nas escolas.

Ainda que o presente estudo traga como inovadora a característica da amostra (adolescente de uma escola militar) e o uso de instrumentos padronizados, há limitações que precisam ser citadas e sugestões de melhoramentos para estudos futuros. A escolha de apenas uma escola, por conveniência, representa uma limitação, já que seria recomendável a inclusão de mais de uma escola militar e, ainda, de outras escolas públicas não militares. Além disso, outros fatores como taxas de distorção idade-série, aspectos familiares e do contexto escolar poderiam ter sido incluídos para a compreensão da motivação para aprender. Estudos futuros podem sanar essas limitações ao constituir uma amostra de forma randômica, incluir outras escolas militares e não militares e propor análises de levem em consideração outros fatores que influenciam na motivação intrínseca e extrínseca dos adolescentes escolares.

\section{Referências}

Angelucci, C. B., Kalmus, J., Paparelli, R., \& Patto, M. H. S. (2004). O estado da arte da pesquisa sobre o fracasso escolar (1991-2002): Um estudo introdutório. Educação e Pesquisa, 30(1), 51-72. doi:10.1590/S1517-97022004000100004

Benevides, A. A. \& Soares, R. B. (2016). Diferencial de desempenho das escolas militares: bons alunos ou boa escola? In Anais do XXI Encontro Regional de Economia (pp. 1-24). (DOI INEXISTENTE)

Bonfim, A. P., Damasceno, A. B., Soares, L. S. S., Rodrigues, L. C., \& Fernandes, S. S. (2017). Influência da administração militar nas escolas públicas de ensino médio. Id On Line Revista Multidisciplinar e de Psicologia, 11(37), 484-499. doi:10.14295/idonline.v11i37.854

Boruchovitch, E. (2008). A motivação para aprender de estudantes em cursos de formação de professores. Educação, 31(1), 30-38. (DOI INEXISTENTE) 
Bzuneck, J. A. (2009). A motivação do aluno: Aspectos introdutórios. In E. Boruchovitch, \& J. A. Bzuneck (Org.), A motivação do aluno: Contribuições da psicologia contemporânea (pp. 9-36). Petrópolis, RJ: Vozes. (DOI INEXISTENTE)

Bzuneck. J. A (2010). Como motivar os alunos: Sugestões práticas. In E. Boruchovitch, J. A. Bzuneck, \& S. E. R. Guimarães. (Org). A motivação para aprender: aplicações no contexto educativo (pp. 13-42). Petrópolis, RJ: Vozes.

Castells, M. (2000). O Poder da Identidade. São Paulo, SP: Paz e Terra.

Damiani, M. (2006). Discurso pedagógico e fracasso escolar. Ensaio: Avaliação e Políticas Públicas em Educação, 14(53), 457-478. doi:10.1590/S0104-40362006000400004

DeBacker, T., \& Nelson, R. M. (2000). Motivation to learn science: Differences related to gender, class type, and ability. The Journal of Educational Research, 93(4), 245-254. doi:10.1080/00220670009598713

Eccheli, S. D. (2008). A motivação como prevenção da indisciplina. Educar, 1(32), 199-213. (DOI INEXISTENTE)

Guimarães, S. E. R., Bzuneck, A. J., \& Sanches, S. F. (2002). Psicologia educacional nos cursos de licenciatura: A motivação dos estudantes. Psicologia Escolar e Educacional, 1(6), 11-19. doi:10.1590/S1413-85572002000100002

Haguette, A., Pessoa, M. K. M., \& Vidal, E. M. (2016). Dez escolas, dois padrões de qualidade. Uma pesquisa em dez escolas públicas de Ensino Médio do Estado do Ceará. Ensaio: Avaliação Política Pública Educaciona, 24(92), 609-636, doi:10.1590/S0104-40362016000300005

Instituto Nacional de Estudos e Pesquisas Educacionais Anísio Teixeira [INEP] e Ministério da Educação (2018). Censo Escolar 2017. Recuperado de https://drive.google.com/file/d/1diB1miZTKvuVByb9oXIXJgWbIW3xLL_f/view

Kolenc, J. (2011). Differences among university students in motivation to learn: A cross-cultural study. Zbornik Instituta za Pedagoška Istraživanja, 43(1), 41-62. doi:10.2298/ZIPI1101041K

Locatelli, A. C. D., Bzuneck, J. A., \& Guimarães, E. R. (2007). A motivação de adolescentes em relação com a perspectiva de tempo futuro. Psicologia: Reflexões e Crítica, 20(2), 268-276. doi:10.1590/S0102-79722007000200013

Lourenço, A. \& De Paiva, M. (2010). A motivação escolar e o processo de aprendizagem. Ciência \& Cognição, 15(2), 132-141. (DOI INEXISTENTE)

Marchiore, L. W. O. A. \& Alencar, E. M. L. S (2009). A motivação para aprender em alunos do ensino médio. Revista Educação Temática Digital, 10(1), 105-123. doi:10.20396/etd.v10in.esp..937

Miguel, R. R., Rijo, D., \& Lima, L. N. (2014). Fatores de risco para o insucesso escolar: a relevância das variáveis psicológica e comportamentais do aluno. Revista Portuguesa de Pedagogia, 1(46), 127-143. (DOI INEXISTENTE)

Moreira, A. B. \& Kramer, S. (2007). Contemporaneidade, educação e tecnologia. Educação \& Sociedade, 28(100), 1037-1057. doi:10.1590/S0101-73302007000300019

Neves, E. R. C. \& Boruchovitch, E. (2007). Escala de avaliação da motivação para aprender de alunos do ensino fundamental. Revista Psicologia Reflexão e Crítica, 20(3), 406-413. doi:10.1590/S0102-79722007000300008

Neves, E. R. C. \& Boruchovitch, E. (2004). A motivação de alunos no contexto da progressão continuada. Psicologia: Teoria e Pesquisa, 20(1), 77-85. doi:10.1590/S0102-37722004000100010

Pansera, S. M., Valentini, N. C., Souza, M. S., \& Berleze, A. (2016). Motivação intrínseca e extrínseca: Diferenças no sexo e na idade. Psicologia Escolar e Educacional, 20(2), 313-320. doi:10.1590/2175-3539/2015/0202972

Pezzi, F. A. S., Donelli, T. M. S., \& Marin, A. H. (2016). School failure in the perception of adolescents, parents and teachers. Psico-USF, 21(2), 319-330. doi:10.1590/1413-82712016210209

Prata, A., Barbosa-Ducharne, M., Gonçalves, C., \& Cruz, O. (2013). O impacto dos estilos educativos parentais e do desenvolvimento vocacional no rendimento escolar de adolescentes. Análise Psicológica, 3(31), 235-243. doi:10.14417/S0870-8231201300030002

Rufini, S.E., Bzuneck, J. A., \& Oliveira, K.L. (2012). A qualidade da motivação em estudantes do ensino fundamental. Paidéia, 22(51), 53-62. doi:10.1590/S0103-863X2012000100007

Schulze, S., \& Van Heerden, M. (2015). Learning matter: Identifying influences on the motivation to learn Science. South African Journal of Education, 35(2), 1-9. doi:10.15700/saje.v35n2a1058

Schwartz, S. (2014). Motivação para ensinar e aprender: Teoria e prática. Petrópolis, RJ: Vozes. (DOI INEXISTENTE)

Yi-Guang Lin, Y-G, McKeachie, W., \& Kim. Y-C. (2003). College student intrinsic and/or extrinsic motivation and learning. Learning and Individual Differences, 13, 251-258. doi:10.1016/S1041-6080(02)00092-4

Zardeckaite-Matulaitiene, K. \& Paluckaite, U. (2013). The relation between teacher's self-disclosure and student's motivation to learn. European Scientific Journal, 9(28), 456-470. doi:10.1080/08824090902861523

Dados dos autores:

Ana Carla Marostica de Souza - Psicóloga, IMED.

Aline Cardoso Siqueira - Doutora, Universidade Federal de Santa Maria.

Israel Kujawa - Doutor, IMED.

Naiana Dapieve Patias - Doutora, IMED.

Endereço para correspondência:

Naiana Dapieve Patias

Rua Senador Pinehrio, 304 - Sala dos Professores IMED

99070-220, Passo Fundo, RS, Brasil

E-mail: naipatias@hotmail.com

Recebido em: 28/11/2016

Aceito em: $31 / 08 / 2018$

Publicado em: 09/05/2019 